\title{
Analysis of clinical efficiency and early postoperative complications after cranioplasty
}

\author{
Hanko M, Cmarkova K, Hanzel R, Snopko P, Opsenak R, Kolarovszki B \\ Clinic of Neurosurgery, Jessenius Faculty of Medicine in Martin, Comenius University in Bratislava \\ and University Hospital in Martin, Slovakia.m.hanko.to@gmail.com
}

\begin{abstract}
INTRODUCTION: Despite of being considered a routine procedure, cranioplasty is associated with a substantial risk of failure, or postoperative complications.

PATIENTS AND METHODS: Postoperative clinical course and rate of complications was assessed in patients undergoing cranioplasty during years 2015-2019 in a retrospective fashion.

RESULTS: The most frequent condition requiring cranioplasty was a presence of bone defect after a decompressive craniectomy for traumatic brain injury (45 patients). Revision was needed in 9 cases (12.68\%), removal of the bone flap was necessary in 5 patients $(7.04 \%)$. The most common complication observed was an unintended intraoperative durotomy, occurring in 9 patients $(12.68 \%)$, which was, however, not associated with an increased risk of reoperation. Postoperative improvement of motor functions was observed in 7 patients $(9.86 \%)$. Improvement of consciousness occurred in 8 patients (11.27\%). Early cranioplasty was associated with significantly higher odds for surgical revision, patients after previous craniectomy for traumatic brain injury had significantly increased odds for the overall occurrence of complications.

CONCLUSIONS: After a cranial reconstruction, complications with a various degree of severity may occur and even the result in need of the implant removal. Postoperative improvement of focal neuro-deficit is possible as well as improvement on the level of patient's consciousness (Tab. 2, Fig. 2, Ref. 61). Text in PDF www.elis.sk

KEY WORDS: cranioplasty, craniectomy, outcome, complications.
\end{abstract}

\section{Introduction}

In neurosurgical practice, we frequently encounter patients with a need of cranial vault reconstruction. This condition might follow a bone flap removal after its infection or tumorous infiltration; however, the most typical scenario is represented by a cranial defect after a decompressive craniectomy. Negative prognostic value of elevated intracranial pressure with regards to patient's prognosis is well described (1). Decompressive craniectomy is able to provide a quick reduction of the intracranial pressure and improvement of brain tissue oxygenation (2). As such, decompressive craniectomy is routinely used in the treatment of neurosurgical emergencies associated with intracranial expansive lesions with a presence or anticipation of brain oedema. This procedure

Clinic of Neurosurgery, Jessenius Faculty of Medicine in Martin, Comenius University in Bratislava and University Hospital in Martin, Slovakia

Address for correspondence: $\mathrm{M}$. Hanko, MD, $\mathrm{PhD}$, Clinic of Neurosurgery, Jessenius Faculty of Medicine in Martin, Comenius University in Bratislava and University Hospital in Martin, Kollarova 2, SK-036 59 Martin, Slovakia.

Phone: +421.910301381

Acknowledgement: This work was supported by following Grants of Comenius University in Bratislava: Dynamics and risk factors of progression in posttraumatic intracerebral haematomas - a comparison of surgical and conservative treatment, UK/136/2019, UK/11/2020. is, however, associated with a considerable postoperative morbidity and complications (3). There is also an obvious need for a later cranial reconstruction in the surviving. In carefully indicated patients, an alternative to craniectomy exists in evacuating of the expansive lesions using a standard craniotomy or decompressive (hinge) craniotomy (4). Nevertheless, decompressive craniectomy remains a widely used procedure. Following this surgery, the intracranial space is converted into an "open box". This results in a loss of natural regulations of cerebrospinal fluid circulation and a postural intracranial pressure control (5) with a possible formation of subdural fluid collections and even hydrocephalus $(5,6)$. Also, hypoperfusion and a decreased metabolism associated with cranial defects were observed in both decompressed and contralateral hemisphere (7) accompanied by various forms of neurological dysfunction, typically linked to diagnoses such as "syndrome of trephined", "sinking skin flap syndrome" or "motor trephine syndrome" (8-10). Such conditions might be later restored by the means of cranial reconstruction, which is associated with an improved cerebral perfusion, oxygenation, and metabolism as well as with normalization of the cerebrospinal fluid circulation (11-13). Based on these observations, a potential of further neurological improvement exists in patients undergoing the reconstruction of the cranial vault $(8,10)$. These observations underline the fact, that cranioplasty is not only a cosmetic or protective, but also a therapeutic procedure. However, despite of being considered a routine 
461-468

operation, cranioplasty is not without a risk of failure or development of postoperative complications. Therefore, our aim was to describe the rate and severity of these complications as well as associated risk factors. We were also interested in the specification of the clinical effect and potential neurological benefit of cranioplasty procedures. In order to achieve these results, we present a 5-year experience of a Slovak academic centre.

\section{Patients and methods}

\section{Included patients and recorded variables}

In this retrospective study, 71 adult (18 years and older) patients, who underwent a cranial reconstruction at Clinic of Neurosurgery, Jessenius Faculty of Medicine in Martin, University Hospital in Martin during the 5-year period of 2015-2019 were included. Patient's demographic data and their preoperative clinical status: level of consciousness quantified by Glasgow Coma Scale (GCS), motor deficit quantified by the simplified Medical Research Council (MRC) muscle strength scale, cranial nerve palsy, phatic disorder and seizure history were recorded as well as selected possible risk factors for complications including diabetes mellitus, arterial hypertension, ischemic heart disease, chronic kidney disease, bronchial asthma or chronic obstructive pulmonary disease, metabolically active hepatopathy, hypothyroidism, history of malignancy (neurological or systemic) and history of a possible alcohol abuse. We also recorded the primary diagnosis associated with the cranial defect (in most patients the reason for previous decompressive craniectomy). Postoperative complications occurring during the first 3 postoperative months as well as patient's neurological status - consciousness, focal neurological findings, possible peristing seizures, were assessed during the outpatient control or during the necessary repeated hospitalization.

\section{Procedure details}

Patients underwent either uni- or bilateral cranioplasty. Skin incision copied the skin flap from the previous surgery and was extended if necessary. After separation and mobilization of the skin flap from the underlying dura, dissection of the temporalis muscle was performed. Any dural tears with or without cerebrospinal fluid leak were recorded and repaired. As a material for the cranial reconstruction, we used autologous bone flaps (previously stored in freezer), 3D printed titanium-alloy implants (Biomedi-

Tab. 1. Preoperative characteristics of included patients $(n=71)$, details of the surgical procedure.

\begin{tabular}{|c|c|c|c|c|c|}
\hline & & Number & $\%$ & Mean & Median \\
\hline \multirow{2}{*}{ Sex } & male & 54 & 76.06 & $\mathrm{x}$ & $\mathrm{x}$ \\
\hline & female & 17 & 23.94 & $\mathrm{x}$ & $\mathrm{X}$ \\
\hline Age (years) & $\mathrm{x}$ & $\mathrm{x}$ & $\mathrm{x}$ & $49,46 \pm 15,01$ & 50 \\
\hline \multirow{9}{*}{$\begin{array}{l}\text { Primary diagnosis } \\
\text { (indication for } \\
\text { craniectomy) }\end{array}$} & traumatic brain injury & 45 & 63.38 & $\mathrm{x}$ & $\mathrm{x}$ \\
\hline & intracerebral haemorrhage & 8 & 11.27 & $\mathrm{x}$ & $\mathrm{x}$ \\
\hline & subarachnoid haemorrhage & 3 & 4.23 & $\mathrm{x}$ & $\mathrm{x}$ \\
\hline & middle cerebral artery infarction & 4 & 5.63 & $\mathrm{x}$ & $\mathrm{x}$ \\
\hline & venous sinus thrombosis & 1 & 1.4 & $\mathrm{x}$ & $\mathrm{x}$ \\
\hline & non-traumatic subdural hematoma & 3 & 4.23 & $\mathrm{x}$ & $\mathrm{x}$ \\
\hline & subdural empyema & 1 & 1.4 & $\mathrm{x}$ & $\mathrm{x}$ \\
\hline & intracerebral haemorrhage after tumour resection & 5 & 7.4 & $\mathrm{x}$ & $\mathrm{x}$ \\
\hline & congenital defect (no craniectomy) & 1 & 1.4 & $\mathrm{x}$ & $\mathrm{x}$ \\
\hline \multirow{7}{*}{ Comorbidities } & arterial hypertension & 34 & 47.89 & $\mathrm{x}$ & $\mathrm{x}$ \\
\hline & ischemic heart disease & 6 & 8.45 & $\mathrm{x}$ & $\mathrm{x}$ \\
\hline & chronic liver disease & 19 & 26.76 & $\mathrm{x}$ & $\mathrm{x}$ \\
\hline & asthma/chronic obstructive pulmonary disease & 3 & 4.23 & $\mathrm{x}$ & $\mathrm{x}$ \\
\hline & hypothyroidism & 1 & 1.4 & $\mathrm{x}$ & $\mathrm{x}$ \\
\hline & diabetes mellitus & 3 & 4.23 & $\mathrm{x}$ & $\mathrm{x}$ \\
\hline & alcohol abuse & 10 & 14.8 & $\mathrm{x}$ & $\mathrm{x}$ \\
\hline \multirow{7}{*}{$\begin{array}{l}\text { Preoperative } \\
\text { neurological } \\
\text { status }\end{array}$} & GCS & $\mathrm{x}$ & $\mathrm{x}$ & $13.66 \pm 2.3$ & 15 \\
\hline & hemiparesis & 31 & 43.66 & $\mathrm{x}$ & $\mathrm{x}$ \\
\hline & cranial nerve palsy & 13 & 18.30 & $\mathrm{x}$ & $\mathrm{x}$ \\
\hline & phatic disorder & 11 & 15.49 & $\mathrm{x}$ & $\mathrm{x}$ \\
\hline & ventriculomegaly & 3 & 4.23 & $\mathrm{x}$ & $\mathrm{x}$ \\
\hline & sinking skin flap & 27 & 38.03 & $\mathrm{x}$ & $\mathrm{x}$ \\
\hline & seizures & 20 & 28.17 & $\mathrm{x}$ & $\mathrm{x}$ \\
\hline \multirow{4}{*}{ Procedure details } & unilateral & 67 & 94.37 & $\mathrm{x}$ & $\mathrm{x}$ \\
\hline & bilateral & 4 & 5.63 & $\mathrm{x}$ & $\mathrm{x}$ \\
\hline & duration (minutes) & $\mathrm{x}$ & $\mathrm{x}$ & $82.92 \pm 39.86$ & 80 \\
\hline & timing (months) & $\mathrm{x}$ & $\mathrm{x}$ & $9.32 \pm 16.65$ & 6 \\
\hline Material used & $3 \mathrm{D}$ printed titanium alloy & 24 & 33.80 & $\mathrm{x}$ & $\mathrm{x}$ \\
\hline & bone cement & 2 & 2.82 & $\mathrm{x}$ & $\mathrm{x}$ \\
\hline
\end{tabular}


cal Engineering, Košice, Slovakia) or bone cement. Holes were present in all implants in order to drain-out the possible epidural fluid collections. Autologous bone flaps and cement implants were fixed either by sutures, in later period we started to use titanium mini plates. Temporalis muscle was subsequently sutured to adjacent galea and subgaleal drainage was used in all cases. Surgical wounds were sutured in layered fashion using interrupted sutures. Details regarding the procedure's timing, duration and intraoperative complications were recorded.

\section{Statistical analysis}

Statistical software MedCalc ${ }^{\circledR}$ 10.2.0.0 (Ostend, Belgium) was used for calculations. Categorical variables were summarized using their frequency in the assessed cohort, continuous variables were summarized by their mean \pm standard deviation and the median values. Differences between the normally distributed characteristics (as confirmed by Shapiro-Wilk test) in independent subgroups were calculated using the unpaired t-test for two samples or ANOVA for more samples. Relationship between the recorded variables and patient's clinical outcome and complications was subsequently assessed using a multivariate logistic regression with Odds ratio (OR), $95 \%$ Confidence interval $(95 \% \mathrm{CI})$ to describe each particular variable. Overall fitness of the regression model was established by the means of Chi-square and p-value. Value of $\mathrm{p} \leq 0.05$ was determined as statistically significant.

\section{Results}

\section{Characteristics of the patients:}

Altogether, there were 71 patients in this study with significantly more men than women included ( 54 vs $17 ; \mathrm{p}<0.001$, t-test). Their mean age was $49.46 \pm 15.01$, the median value reached 50 years. The most frequent condition requiring a cranial reconstruction was the presence of cranial defect after decompressive craniectomy for traumatic brain injury ( 45 patients, $63.38 \%$ ). The three most frequent comorbidities were: arterial hypertension (34 patients, $47.89 \%$ ), chronic liver disease (19 patients, $26.76 \%$ ), ischemic heart disease ( 6 patients, $8.45 \%$ ). History of alcohol abuse was recorded in 10 patients $(14.08 \%)$ ). As for clinical findings, the mean value of preoperative GCS reached $13.66 \pm 2.3$, the median value was 15 , history of seizures was positive in 20 patients $(28.17 \%)$, signs of the sinking skin flap syndrome were present in 27 patients (38.03\%). Hemiparesis was present in 31 patients (43.66\%), cranial nerve palsy in $13(18.30 \%)$, phatic disorder in 11 patients $(15.49 \%)$. In 62 patients $(87.32 \%)$, this was the first cranial reconstruction, 9 patients $(12.68 \%)$ were indicated for the cranioplasty due to a failure of previous reconstruction. In 4 patients $(5.63 \%)$, the reconstruction was bilateral. Cranioplasty was defined as early if performed during the first 120 days after craniectomy, this scenario happened in 22 patients $(30.99 \%)$. The average duration of the surgery was $82.92 \pm 39.86$ minutes, the median reached 80 minutes. For cranial reconstruction, we used an autologous bone flap in 45 cases $(63.38 \%)$, 3D printed titanium alloy implant in 24 cases $(33.80 \%)$ and bone cement in 2 cases $(2.82 \%)$. No significant difference was observed, when comparing the duration of

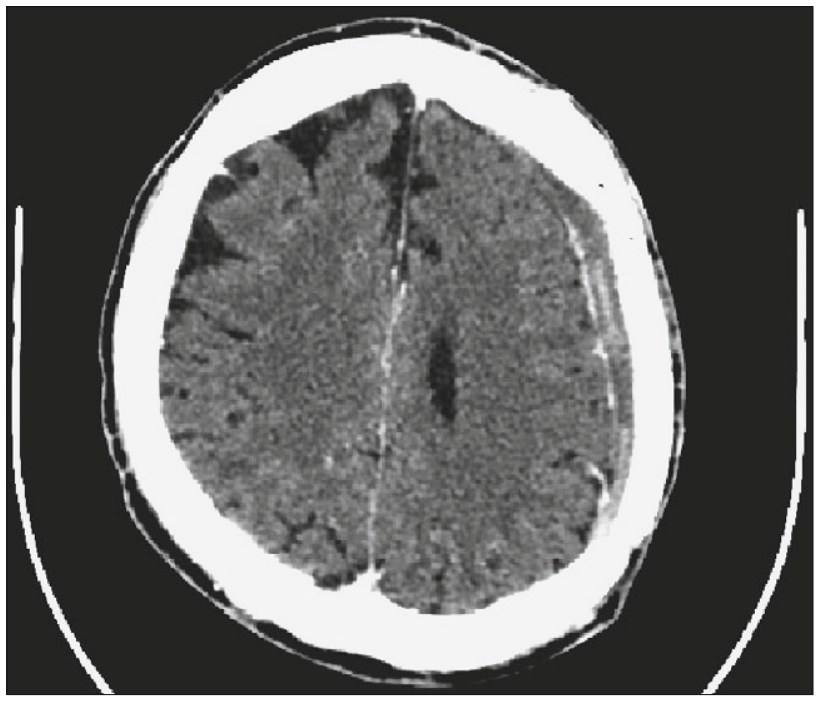

Fig. 1. Postoperative head CT of patient after left-sided cranioplasty complicated by intraoperative skin flap perforation and subsequent skin flap necrosis. A contrast-enhancing epidural collection is visible underlying the implanted bone flap. Epidural abscess was confirmed during surgical revision.

the surgery according to the material used $(78.06 \pm 28.33$ vs 85.33 \pm 47.19 vs $136 \pm 36.77$ minutes respectively; $p=0.43)$. A complete characteristic of our patients is summarized in the Table 1.

\section{Clinical results}

Mortality of this elective surgery reached zero. At the end of the follow-up period, we observed an improvement of GCS in 8 patients $(11.27 \%)$, the mean value was $13.84 \pm 2.27$, the median remained at 15 . Motor improvement quantified by simplified MRC scale occurred in 7 (9.86\%) of our patients. Of 20 patients with a preoperative history of seizures, in 13 (18.31\%) of them an adequate postoperative control of epilepsy was achieved. New seizures were observed in $2(2.82 \%)$ patients. Phatic disorders and cranial nerve palsies remained unchanged. The final score in modified Rankin scale reached the mean value of $0.96 \pm 1.72$ and the median value was 0 . Multivariate logistic regression analysis was not able to detect any possible positive or negative factor associated with an improvement of neither motor functions, nor consciousness ( $p>0.05,95 \% \mathrm{CI}$ including value of 1 ).

\section{Complications, reoperations and risk factors}

At least one complication (regardless of its severity) was observed in 35 (49.3\%) patients. The most common complication observed was an unintended intraoperative durotomy, which occurred in 9 patients $(12.68 \%)$, none of these patients required a surgical revision. Intraoperative perforation of the skin flap occurred in a single patient (1.4\%), who later required repeated revisions and bone flap removal due to the skin flap ulceration with bone flap osteomyelitis and epidural abscess (Fig. 1). Major postoperative complications requiring a surgical revision occurred in 9 patients $(12.68 \%)$. A removal of the implant was necessary in 5 patients 
461-468

Tab. 2. A summary of recorded complications, need for surgical revision and implant removal. Altogether, 9 revisions, 2 ventriculoperitoneal shunt insertions and 5 implant removals were performed.

\begin{tabular}{llcccc}
\hline \multirow{2}{*}{ Complication } & & Number & $\%$ & Revision & $\begin{array}{c}\text { Implant } \\
\text { removal }\end{array}$ \\
\hline \multirow{2}{*}{ intraoperative } & unintended durotomy & 9 & 12.68 & 0 & 0 \\
& skin flap perforation & 1 & 1.4 & 1 & 1 \\
\hline & extradural fluid collection & 7 & 9.86 & 4 & 3 \\
& subcutaneous hematoma & 3 & 4.23 & 0 & 0 \\
& wound dehiscence & 3 & 4.23 & 0 & 0 \\
& new seizures & 2 & 2.82 & 0 & 0 \\
& implant malposition & 2 & 2.82 & 1 & 0 \\
& subdural hematoma & 2 & 2.82 & 0 & 0 \\
& skin flap necrosis/ulceration & 2 & 2.82 & 1 & 1 \\
& superficial surgical site infection & 2 & 2.82 & 2 & 2 \\
& intracerebral hematoma & 1 & 1.4 & 1 & 0 \\
& epidural abscess & 1 & 1.4 & 1 & 1 \\
& bone flap infection & 1 & 1.4 & 1 & 1 \\
& cerebrospinal fluid leak & 1 & 1.4 & 0 & 0 \\
\hline hydrocephalus & & 2 & 2.82 & 2 VP shunts & 0 \\
\hline
\end{tabular}

lism with an associated possible neurological dysfunction occur, often accompanied by "sinking skin flap" $(7,8,11,12,17)$. Besides of this, oedema and penetration of cerebrospinal fluid into post-contusion foci with a subsequent worsening of motor functions was described as "motor trephine syndrome". Several mostly subjective disorders following craniectomy describe a long known "syndrome of the trephined" $(8,9)$. It is important, that especially an early cranioplasty has a potential to reverse these symptoms and improve metabolism, perfusion and dysfunction of the affected brain tissue $(7,8,10-12)$. Associated motor and cognitive improvements were reported in several studies assessing the outcome of patients undergoing cranioplasty (17-22). Such observation was present in

(7.04 \%), specifically one titanium alloy implant, one cement implant and three autologous bone flaps were removed. Another 2 of 3 patients with preoperatively present ventriculomegaly underwent an insertion of ventriculoperitoneal shunt, which was carried out simultaneously with cranioplasty in one case. Hydrocephalus was, however, not considered to be a true complication of cranioplasty but rather a natural consequence of the preoperative condition. The most frequent reason for a surgical revision was a development of postoperative extradural fluid collection in 4 patients $(5.64 \%)$. A complete summary of complications and details of surgical revision is shown in the Table 2. Multivariate logistic regression revealed higher odds for overall complications rate in patients after decompressive craniectomy for traumatic brain injury (OR 2.75, 95\%CI 1.028-7.376, $\mathrm{p}=0.044$, Chi-square for overall model fit: $\mathrm{p}=0.04)$. Also, an early cranioplasty was associated with increased odds for necessity of surgical revision (OR 5.75, $95 \%$ CI 1.285-25.722, $\mathrm{p}=0.022$, Chi-square for overall model fit: $p=0.017$ ). No risk or protective factor associated with any of observed complications was detected by the multivariate logistic regression ( $p>0.05,95 \% \mathrm{CI}$ including value of 1$)$. This included no statistically significant effect of the intraoperative complications, procedure's duration, or material of the implant on the occurrence of postoperative complications.

\section{Discussion}

The most common reasons for not performing cranioplasty are death and a poor neurological condition of the surviving patients such as: vegetative state or unfavourable prognosis of long-term survival (14). Otherwise, cranioplasty is performed not only as cosmetic or protective procedure, but also as a therapeutic one. A restoration of cranial vault has a potential to normalize cerebrospinal fluid circulation and to avoid the need for shunt procedure due to hydrocephalus, factor associated with a worse neurological outcome $(13,15,16)$. Also, it has been described, that in patients after craniectomy, a decreased perfusion and metabo- our cohort as well. We observed a motor improvement in $9.86 \%$ and an improvement of consciousness in $11.27 \%$ of our patients. Simple statistical comparison of pre- and postoperative clinical status would, however, produce vague and inaccurate results due to heterogenicity of preoperative clinical symptomatology (such as none to severe motor deficit) and primary diagnoses in our cohort. For example, in patients after traumatic brain injury, its lesser severity results in a more remarkable neurological improvement (18). Also, the location of previous contusions, intracerebral hematomas or ischemic lesions would undoubtedly matter. An objective improvement may occur in up to $40 \%$ of patients after cranioplasty (22). As the most important observation we consider the proof that this improvement is possible, despite the fact that we were not able to distinguish a subgroup of patients, who achieved the most significant improvement. Even though we did not observe any improvement of phatic disorders in our group, this is potentially possible even in late cranioplasty (19). Nevertheless, the effect of proper rehabilitation and postoperative care is crucial in order to obtain satisfactory functional results (21).

Zero postoperative mortality observed in our cohort is not a matter of course, as repeated interventions for complications, bifrontal location of cranioplasty, seizures and diabetes act as risk factors (23). Postoperative mortality in cranioplasty patients reaches $2.3-3.16 \%(23,24)$. We observed the overall rate of complications of $49.3 \%$. This high number mostly reflects the inclusion criteria and not the severity of the particular complication, as many of those can be managed in a conservative fashion and local treatment. Several other works reported a considerably high morbidity in patients after cranioplasty with the complications rate ranging from $18.2 \%$ to $40.8 \%(22,23,25-27)$. The increased odds for reoperation in patients undergoing an early cranioplasty and the increased odds for overall complications rate observed in our patients after previous traumatic brain injury are similar to those of Goedemans, who identified a previously evacuated acute subdural hematoma as a risk factor for postoperative complications, with other risk factors being an early cranioplasty within 3 months and 
preoperative hydrocephalus (27). Early cranioplasty also results in an increased risk of reoperation need according to Paredes et al (22). Other factors associated with the increased odds for reoperation include a higher age $(22,23)$, hemorrhagic stroke, arterial hypertension (23) and smoking (28). Naturally, it is expected to encounter an increased rate of complications in revision cranioplasties (29). We have not obtained similar results, most likely due to a limited number of revision-type cranial reconstructions in our cohort. Early cranioplasty is, however, recommended when possible, as it is associated with a better functional outcome $(28,30)$ and possibility of restoring normal cerebrospinal fluid circulation, thus avoiding the need of shunting $(13,15,31)$. As various authors use different definitions of early cranioplasty, a proper determination of ideal timing for cranial reconstruction to achieve the best neurological improvement and to reduce the risk of complications is necessary. The study by Kim et al. suggested a much shorter interval with maximum of 45 days after craniectomy, when compared to our definition, justifying it by an observed reduced rate of bone flap resorption and surgical site infections (32). It is, however, necessary to note that according to our own experience, numerous patients may not be capable of undergoing cranial reconstruction during this short interval after craniectomy.

The inclusion of hydrocephalus into the group of complications is disputable since it may represent a consequence of primary injury such as: trauma or subarachnoid haemorrhage and may also result from disturbed dynamics of cerebrospinal fluid circulation, which follows craniectomy $(31,33)$. It is therefore possible to encounter the patients who, as opposed to the patients with sunken skin flaps, present with ventriculomegaly and persistent prominence of the brain tissue through craniectomy. Shunts can be implanted simultaneously during the cranial reconstruction procedure or as a second surgical step, if necessary. Simultaneous cranioplasty and implantation of ventriculoperitoneal shunt was repeatedly reported to be a risk factor for the increased complications rate $(34,35)$, more recent reports. However, we did not reach this conclusion and therefore agree with recommendation of simultaneous procedure in carefully selected patients $(36,37)$. On the other hand, a shunting procedure after a decompressive craniectomy prior to cranioplasty can provoke sinking skin flap syndrome and implantation of programmable valves is therefore recommended (37). In traumatic brain injured patients, cerebrospinal fluid dynamics might be restored by an early cranioplasty and subsequent shunting is therefore not required $(13,15)$. An adequate treatment of postcraniectomy hydrocephalus remains crucial since it is associated with a worse neurological outcome $(13,16)$ and with an increased risk of bone flap resorption after cranioplasty (25).

Regarding specific complications, an intraoperative dural tear occurring during skin flap separation was recorded as the most frequent one in our cohort. During the cranioplasty procedure, skin flap preparation is especially difficult because of postoperative fibrosis between dura (and augmentative duraplasty), temporalis muscle and pericranium or galea that develops after previous decompressive craniectomy. We did not observe any significant association of the intraoperative dural tear with neither a need of surgical revision nor development of any other postoperative complication. It has, however, been observed that intraoperative dural tears may result in a formation of postoperative epidural fluid collections (38). Anyway, intraoperative dural tear remains an undesired condition. Therefore, various techniques were developed in order to reduce the operating time, facilitate skin flap and temporalis muscle dissection and to reduce a formation of fibrous adhesions, mostly by means of overlaying of the decompressed area by antiadhesive materials, bovine pericardium or synthetic dural substitutes, thus creating an artificial plane between dura and skin flap, which can be followed during the dissection $(39,40)$.

The most frequent indication for a surgical revision was development of expansive extradural fluid or haemorrhagic collection. Its incidence may reach up to $37.3 \%$ (41). According to Jeong, this condition was associated with the size of cranioplasty and intraoperative cerebrospinal fluid leak (38). Lee also described a preoperative dural calcification and postoperative epidural air bubbles as possible risk factors associated with an increased dural stiffness and possible subsequent inflammatory response accompanied by an epidural fluid exudation (41). An intracerebral haemorrhage after cranioplasty was observed in one of our patients. This condition counts amongst the less frequent postoperative complications and is most likely explainable as the consequence of a reperfusion injury $(11,42)$. As already mentioned, autoregulatory mechanisms of the intracranial space are impaired during the post-craniectomy period, often associated with a cerebral hypoperfusion and sinking skin flap syndrome $(8,11,12)$. After a longer period, during which the brain was almost directly exposed to atmospheric pressure, the pressure was rapidly alleviated after a cranial vault reconstruction. Despite of a typically positive effect of this pressure change, represented by an improved cerebral metabolism and perfusion (7, $8,11,12)$, the impaired autoregulatory mechanisms in the previously damaged brain tissue may be unable to compensate such radical pressure changes. This results in a reperfusion injury with an increased cerebral volume and even oedema, occasionally accompanied by an intracerebral haemorrhage $(11,42)$.

There is still an ongoing debate about an ideal material used for cranioplasty. It is typical to use autologous bone flap as the first-tier choice $(14,27)$ due to its cost-effectivity and natural biocompatibility. Its use is, however, associated with the increased odds for reoperation (31) and aseptic bone necrosis and resorption, especially in younger patients (43). Bone flap resorption occurs in up to $90 \%$ of patients, is non-linear and its minor degree is considered to be a natural course of bone remodelling and revitalization (43). We did not observe this complication, since it is typically observed with a longer delay after cranioplasty (44), contrary to the methodology of our study, which was aimed to describe early complications. However, extensive bone flap resorption may lead to a complete failure of cranioplasty and require a repeated surgery, a complete revision or augmentation. This occurs in about $22 \%$ of cases during the first 12 months after an autologous bone cranioplasty (44) and in $26 \%$ of cases after 30 months (45). An increased risk for reoperation due to bone flap resorption are associated with younger patients, non-rigid fixation of bone flap and shunt dependent hydrocephalus (25). Bone cement was used as artificial material in 2 of our patients and for most patients with an 

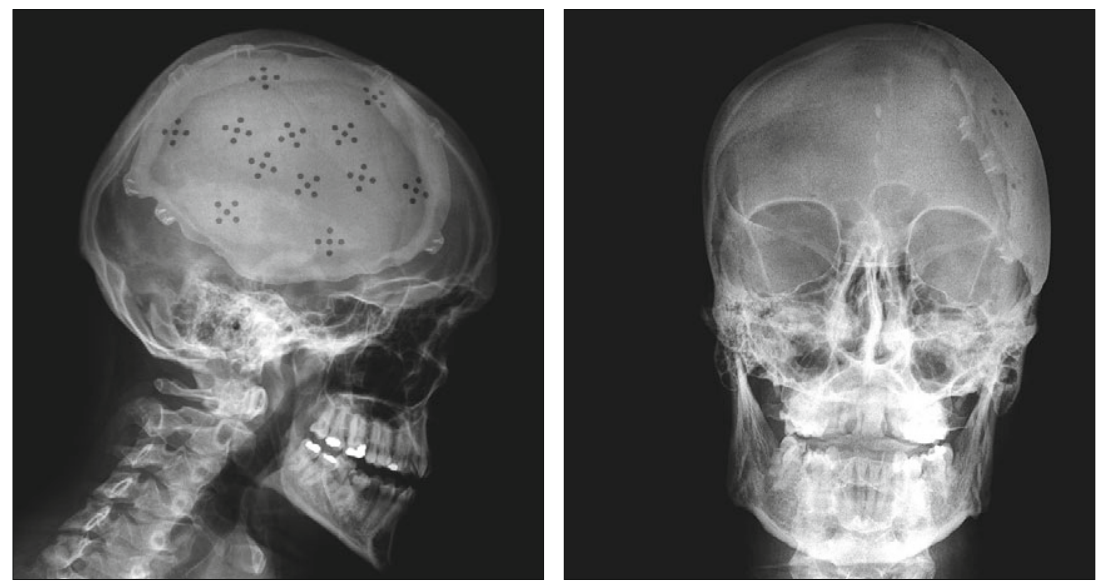

Fig. 2. Illustration of postoperative X-ray after cranioplasty using custom made 3D printed titanium alloy plate.

autologous bone loss due to contamination, damage during head trauma, tumorous infiltration or previous cranioplasty failure due to a resorption or infection we used custom-made 3D printed titanium alloy implants (Fig. 2). Their increased cost and presence of postoperative $\mathrm{CT}$ artifacts are compensated by an achievement of precise reconstruction (46), excellent mechanical durability and low failure rate (47). Nevertheless, infectious complications may occur with incidence up to $16 \%$, especially, when treating large bone defects and patients after previous post-cranioplasty infection (48). When comparing the titanium implants only, the use of 3D printed custom-made implants resulted in more satisfactory results than the use of pre-curved titanium mesh implants, which are more useful in treatment of smaller cranial defects $(48,49)$. Due to their mechanical stability and satisfactory cosmetic results, custom made titanium implants can also be used in the treatment of bone defects after craniofacial or maxillofacial skeleton resections $(50,51)$ or compound injuries, which may be especially difficult to reconstruct $(52,53)$. Also, titanium miniplates became a routine mean of cranial bone flap fixation (54), replacing osteosuture and achieving satisfactory results (54) including a reduced osteolysis and complication rate (25). In paediatric patients, biodegradable plates can be used to fix both cranial bone flaps (55) and dislocated injuries of maxillofacial skeleton, resulting in satisfactory mechanic and cosmetic results as well as in a low complication and reoperation rate (56). Other commonly used materials in cranial reconstructive surgery include polymethylmethacrylate (PMMA), polyetheretherketone (PEEK) or porous hydroxyapatite $(55,57)$. Several studies found no significant difference in the complications occurrence, when comparing the materials used $(22,23)$, according to the recent meta-analysis, risk of postoperative infections and hematoma is similar in all materials with PEEK implants having a lower risk of overall complications and implant exposure (58).

Two skin flap related complications occurred. One small skin flap necrosis was treated by a repeated debridement and successfully managed by a secondary healing, one patient after an intraoperative skin flap perforation developed a skin flap ulceration and a subsequent bone flap osteomyelitis and epidural abscess, which required repeated surgeries and a removal of the bone flap. Skin flap related complications after cranioplasty are often consequences of multiple previous surgeries, post-craniectomy skin flap retraction or intraoperative damage to vascular supply of the skin flap (59). With a subsequent tissue loss and surgical site infections, they often require a complicated management with multiple surgeries utilizing free or advancement flaps (59). The best protective effect against a delayed skin erosion and implant exposure was observed with PEEK implants (58), contrary to an increased risk accompanying PMMA (45). After cranioplasty, surgical site infections incidence ranges from $6.6 \%$ up to $26.43 \%(23,28)$ and we were able to achieve a lower rate. Reported risk factors include age $(23,28)$, repeated interventions, opening of frontal sinus, haemorrhagic stroke and even hydrocephalus (23). Surgical site infections are especially difficult to treat, when extending into bone flap. Such situation requires its removal with a later reoperation using an artificial material.

Seizures are regarded to be one of the most frequent non-surgical complications of cranioplasty with their incidence reaching up to $30.3 \%$ (60). As for our patients, $28.17 \%$ had a history of preoperative seizures with a cranioplasty being able to improve the seizure control with the rate of persistent seizures being reduced to $18.31 \%$. In $2(2.82 \%)$ patients, early postoperative seizures were observed. We were not able to identify any risk factors for early seizures, amongst the known factors there is an increased interval between craniectomy and cranioplasty (60), age and post-contusion brain foci (61). As the damaged areas of brain are known to have a lower epileptogenic threshold (60), we may presume that the early postoperative seizures are the result of a sudden perfusion and metabolism changes that accompany the reconstruction of the cranial vault. When the brain gradually adapts to restored biomechanics of closed intracranial space, incidence of postoperative seizures decreases, as illustrated in our patients.

There are several limitations of this study. Firstly, the number of included patients is limited. It is, however, based on data from five years and therefore provides a solid insight on the overall use of this surgery. The number of patients receiving each type of cranial implant is imbalanced, but naturally reflects the most frequent use of autologous bone flaps. A longer follow up could also reveal delayed postoperative complications such as bone flap resorption.

\section{Conclusions}

Despite of some limitations, we can conclude that even though it is considered a technically simple surgery, cranioplasty is associated with a substantial number of complications. Of these, only a minority is severe enough to require a surgical revision, which, however, occasionally needs to be repeated. A failure of the procedure requiring the implant's removal occurs in about $7 \%$ 
of cases. Differences of clinical results or complications were not observed between autologous bone or artificial material. A successful cranioplasty has potential to improve both patient's level of consciousness and motor deficit. This knowledge is essential to physicians indicating a decompressive craniectomy or deciding between craniectomy, osteoplastic decompressive craniotomy or simple craniotomy for the evacuation of an intracranial mass lesion.

\section{References}

1. Krbila S, Waczulikova I, Sobona V, Zahorec R. Impact of intracranial pressure measurement on survival in patients with severe traumatic brain injury. Bratisl Med J 2013; 114 (12): 696-701.

2. Jaeger M, Soehle M, Meixensberger J. Effects of decompressive craniectomy on brain tissue oxygen in patients with intracranial hypertension. J Neurol Neurosurg Psychiatry 2003; 74 (4): 513-515.

3. Hanko M, Soršák J, Snopko P, Opšenák R, Zeleňák K, Kolarovszki B. Incidence and risk factors of early postoperative complications in patients after decompressive craniectomy: a 5-year experience. Eur J Trauma Emerg Surg 2020, 19. DOI: 10.1007/s00068-020-01367-4.

4. Mraček J, Choc M, Mraček Z. Osteoplastic decompressive craniotomy - an alternative to decompressive craniectomy. Acta Neurochir (Wien) 2011; 153 (11): 2259-2263.

5. Lilja-Cyron A, Andresen M, Kelsen J, Andreasen TH, Fugleholm K, Juhler M. Long-Term Effect of Decompressive Craniectomy on Intracranial Pressure and Possible Implications for Intracranial Fluid Movements. Neurosurgery 2020; 86 (2): 231-240.

6. Aarabi B, Chesler D, Maulucci C, Blacklock T, Alexander M. Dynamics of subdural hygroma following decompressive craniectomy: a comparative study. Neurosurg Focus 2009; 26 (6): E8.

7. Sakamoto S, Eguchi K, Kiura Y, Arita K, Kurisu K. CT perfusion imaging in the syndrome of the sinking skin flap before and after cranioplasty. Clin Neurol Neurosurg 2006; 108 (6): 583-585.

8. Yamaura A, Makino H. Neurological deficits in the presence of the sinking skin flap following decompressive craniectomy. Neurol Med Chir (Tokyo) 1977; 17 (1 Pt 1): 43-53.

9. Grant FC, Norcross NC. Repair of Cranial Defects by Cranioplasty. Ann Surg 1939; 110 (4): 488-512.

10. Stiver SI, Wintermark M, Manley GT. Reversible monoparesis following decompressive hemicraniectomy for traumatic brain injury. J Neurosurg 2008; 109 (2): 245-254.

11. Kato A, Morishima H, Nagashima G. Unexpected complications immediately after cranioplasty. Acute Med Surg 2017; 4 (3): 316-321.

12. Isago T, Nozaki M, Kikuchi Y, Honda T, Nakazawa H. Sinking skin flap syndrome: a case of improved cerebral blood flow after cranioplasty. Ann Plast Surg 2004; 53 (3): 288-92.

13. Nasi D, Dobran M. Can early cranioplasty reduce the incidence of hydrocephalus after decompressive craniectomy? A meta-analysis. Surg Neurol Int 2020; 11: 94. DOI: 10.25259/SNI_120_2020.

14. Hrabovský D, Jančálek R, Říha I, Chrastina J. Komplikace kranioplastik po dekompresivní kraniektomii. Cesk Slov Neurol N 2016; 79/112 (1): 77-81.

15. Ozoner B, Kilic M, Aydin L, Aydin S, Arslan YK, Musluman AM, Yilmaz A. Early cranioplasty associated with a lower rate of post-traumatic hydrocephalus after decompressive craniectomy for traumatic brain injury. Eur J Trauma Emerg Surg 2020; 46 (4): 919-926.
16. Nasi D, Dobran M, Di Rienzo A, di Somma L, Gladi M, Moriconi E, Scerrati M, Iacoangeli M. Decompressive Craniectomy for Traumatic Brain Injury: The Role of Cranioplasty and Hydrocephalus on Outcome. World Neurosurg 2018; 116: e543-e549.

17. Woo PYM, Mak CHK, Mak HKF, Tsang ACO. Neurocognitive recovery and global cerebral perfusion improvement after cranioplasty in chronic sinking skin flap syndrome of 18 years: Case report using arterial spin labelling magnetic resonance perfusion imaging. J Clin Neurosci 2020; 77: 213-217.

18. Jasey N, Ward I, Lequerica A, Chiaravalloti ND. The therapeutic value of cranioplasty in individuals with brain injury. Brain Inj 2018; 32 (3): $318-324$.

19. Jelcic N, Della Puppa A, Mottaran R, Cecchin D, Manara R, Dam M, Cagnin A. Case series evidence for improvement of executive functions after late cranioplasty. Brain Inj 2013; 27 (13-14): 1723-1726.

20. Yaman M, Cihan G, Samanci MY, Arslan E, Antar V. The Evaluation of the Effect of Cranioplasty on Cerebral Metabolism Using F-18 FDG PET/CT. Istanbul Med J 2019; 20 (3): 193-197.

21. Su JH, Wu YH, Guo NW, Huang CF, Li CF, Chen CH, Huang MH. The effect of cranioplasty in cognitive and functional improvement: Experience of post traumatic brain injury inpatient rehabilitation. Kaohsiung $\mathrm{J}$ Med Sci 2017; 33 (7): 344-350.

22. Paredes I, Castaño-León AM, Munarriz PM, Martínez-Perez R, Cepeda S, Sanz R, Alén JF, Lagares A. Cranioplasty after decompressive craniectomy. A prospective series analyzing complications and clinical improvement. Neurocirugia (Astur) 2015; 26 (3): 115-125.

23. Zanaty M, Chalouhi N, Starke RM, Clark SW, Bovenzi CD, Saigh M, Schwartz E, Kunkel ES, Efthimiadis-Budike AS, Jabbour P, Dalyai R, Rosenwasser RH, Tjoumakaris SI. Complications following cranioplasty: incidence and predictors in 348 cases. J Neurosurg 2015; 123 (1): 182-188.

24. Broughton E, Pobereskin L, Whitfield PC. Seven years of cranioplasty in a regional neurosurgical centre. Br J Neurosurg 2014; 28 (1): 34-39.

25. Giese H, Meyer J, Unterberg A, Beynon C. Long-term complications and implant survival rates after cranioplastic surgery: a single-center study of 392 patients. Neurosurg Rev 2020 26. DOI: 10.1007/s10143-020-01374-4.

26. Bobinski L, Koskinen LO, Lindvall P. Complications following cranioplasty using autologous bone or polymethylmethacrylate - retrospective experience from a single center. Clin Neurol Neurosurg 2013; 115 (9): 1788-1791.

27. Goedemans T, Verbaan D, van der Veer $O$ et al. Complications in cranioplasty after decompressive craniectomy: timing of the intervention. Journal of Neurology 2020 May; 267 (5): 1312-1320.

28. Wachter D, Reineke K, Behm T, Rohde V. Cranioplasty after decompressive hemicraniectomy: underestimated surgery-associated complications? Clin Neurol Neurosurg 2013; 115 (8): 1293-1297.

29. Shay T, Belzberg M, Asemota AO, Mitchell KA, Wolff A, Santiago GF, Huang J, Brem H, Gordon CR. Risk of Complications in Primary Versus Revision-Type Cranioplasty. J Craniofac Surg 2020; 31 (2): 423-427.

30. Tasiou A, Vagkopoulos K, Georgiadis I, Brotis AG, Gatos H, Fountas KN. Cranioplasty optimal timing in cases of decompressive craniectomy after severe head injury: a systematic literature review. Interdisciplinary Neurosurg 2014; 1 (4): 107-111.

31. Malcolm JG, Rindler RS, Chu JK, Chokshi F, Grossberg JA, Pradilla G, Ahmad FU. Early Cranioplasty is Associated with Greater Neu- 
$461-468$

rological Improvement: A Systematic Review and Meta-Analysis. Neurosurgery 2018; 82 (3): 278-288.

32. Kim JH, Hwang SY, Kwon TH, Chong K, Yoon WK, Kim JH. Defining "early" cranioplasty to achieve lower complication rates of bone flap failure: resorption and infection. Acta Neurochir (Wien) 2019; 161 (1): 25-31.

33. De Bonis P, Sturiale CL, Anile C, Gaudino S, Mangiola A, Martucci M, Colosimo C, Rigante L, Pompucci A. Decompressive craniectomy, interhemispheric hygroma and hydrocephalus: a timeline of events? Clin Neurol Neurosurg 2013; 115 (8): 1308-1312.

34. Heo J, Park SQ, Cho SJ, Chang JC, Park HK. Evaluation of simultaneous cranioplasty and ventriculoperitoneal shunt procedures. J Neurosurg 2014; 121 (2): 313-318.

35. Schuss P, Borger V, Güresir Á, Vatter H, Güresir E. Cranioplasty and Ventriculoperitoneal Shunt Placement after Decompressive Craniectomy: Staged Surgery Is Associated with Fewer Postoperative Complications. World Neurosurg 2015; 84 (4): 1051-1054.

36. Lin HY, Lin KC, Tsai CC, Wan D. Simultaneous or staged operation? Timing of cranioplasty and ventriculoperitoneal shunt after decompressive craniectomy. Formos J Surg 2019; 52: 122-126.

37. Ting CW, Lu CH, Lan CM, Lee TH, Hsu SW, Su TM. Simultaneous cranioplasty and ventriculoperitoneal shunt placement in patients with traumatic brain injury undergoing unilateral decompressive craniectomy. J Clin Neurosci 2020; 79: 45-50.

38. Jeong SH, Wang US, Kim SW, Ha SW, Kim JK. Symptomatic Epidural Fluid Collection Following Cranioplasty after Decompressive Craniectomy for Traumatic Brain Injury. Korean J Neurotrauma 2016; 12 (1): 6-10.

39. Jeong TS, Kim WK, Jang MJ. Cranioplasty Results after the Use of a Polyester Urethane Dural Substitute (Neuro-Patch () ) as an Adhesion Prevention Material in Traumatic Decompressive Craniectomy. J Trauma Inj 2019; 32 (4): 195-201.

40. Nguyen KD, Reddy V, Rahimi SY. Dural Sandwich Technique for Hemicraniectomy and Benefits During Cranioplasty. World Neurosurg 2019 11: S1878-8750 (19)30030-0. DOI: 10.1016/j.wneu.2018.12.162.

41. Lee JW, Kim JH, Kang HI, Moon BG, Lee SJ, Kim JS. Epidural fluid collection after cranioplasty: fate and predictive factors. J Korean Neurosurg Soc 2011; 50 (3): 231-234.

42. Kwon SM, Cheong JH, Kim JM, Kim CH. Reperfusion injury after autologous cranioplasty in a patient with sinking skin flap syndrome. J Korean Neurosurg Soc 2012; 51 (2): 117-119. DOI: 10.3340/jkns.2012.51.2.117.

43. Korhonen TK, Salokorpi N, Niinimäki J, Serlo W, Lehenkari P, Tetri S. Quantitative and qualitative analysis of bone flap resorption in patients undergoing cranioplasty after decompressive craniectomy. J Neurosurg 2018; 130 (1): 312-321.

44. Honeybul S, Morrison DA, Ho KM, Lind CRP, Geelhoed E. A randomised controlled trial comparing autologous cranioplasty with custommade titanium cranioplasty: long-term follow-up. Acta Neurochir (Wien) 2018; 160 (5): 885-891.

45. Yeap MC, Tu PH, Liu ZH et al. Long-Term Complications of Cranioplasty Using Stored Autologous Bone Graft, Three-Dimensional Polymethyl Methacrylate, or Titanium Mesh After Decompressive Craniectomy: A Single-Center Experience After 596 Procedures. World Neurosurg 2019; 128: e841-e850. DOI: 10.1016/j.wneu.2019.05.005.
46. Francaviglia N, Maugeri R, Odierna Contino A et al. Skull Bone Defects Reconstruction with Custom-Made Titanium Graft shaped with Electron Beam Melting Technology: Preliminary Experience in a Series of Ten Patients. Acta Neurochir Suppl 2017; 124: 137-141.

47. Williams LR, Fan KF, Bentley RP. Custom-made titanium cranioplasty: early and late complications of 151 cranioplasties and review of the literature. Int J Oral Maxillofac Surg 2015; 44 (5): 599-608.

48. Wiggins A, Austerberry R, Morrison D, Ho KM, Honeybul S. Cranioplasty with custom-made titanium plates -14 years experience. Neurosurgery $2013 ; 72$ (2): 248-256.

49. Policicchio D, Casu G, Dipellegrini G, Doda A, Muggianu G, Boccaletti R. Comparison of two different titanium cranioplasty methods: Custom-made titanium prostheses versus precurved titanium mesh. Surg Neurol Int 2020; 11: 148. DOI: 10.25259/SNI_35_2020.

50. Kurinec F, Rudinský B, Marinčák L. Chirurgická liečba rozsiahlej fibróznej dysplázie v kraniofaciálnej oblasti - kazuistika. Cesk Slov Neurol N 2016; 79/112 (6): 723-727.

51. Park JH, Odkhuu M, Cho S, Li J, Park BY, Kim JW. 3D-printed titanium implant with pre-mounted dental implants for mandible reconstruction: a case report. Maxillofac Plast Reconstr Surg 2020; 42: 28. https: // DOI.org/10.1186/s40902-020-00272-5

52. Janíčková M, Statelová D, Malachovský, I.: Textbook of dentistry. Bratislava: Univerzita Komenského, 2015, 230 p.

53. Malachovský I, Straka L, Novomeský F, Statelová D, Janíčková M, Štilla J, Urbanová E.: Atypické strelné poranenie maxilofaciálnej oblasti, Soud Lék 2011; 56 (1): 2-4.

54. Junaid M, Bukhari SS, Saeed MA, Rashid MU. Mini titanium plates; hearkening the end of non-rigid cranial bone flap fixation. Pak J Med Sci 2017; 33 (4): 915-919.

55. Son S, Park CW, Kim EY, Kim JM, Yoo Cj. Bone Resorption of Autologous Cranioplasty Following Decompressive Craniectomy in Children. J Kor Neurotraumatol Soc 2009; 5: 118-123.

56. Janickova M, Statelova D, Mikuskova K, Jesenak M, Malachovsky I. Biodegradable versus titanium plates and screws for paediatric facial skeleton fractures. Bratisl Lek Listy 2018; 119 (9): 554-559.

57. Iaccarino C, Kolias AG, Roumy LG, Fountas K, Adeleye AO. Cranioplasty Following Decompressive Craniectomy. Front Neurol 2020; 10: 1357. DOI: 10.3389/fneur.2019.01357.

58. Liu L, Lu ST, Liu AH et al. Comparison of complications in cranioplasty with various materials: a systematic review and meta-analysis. Br J Neurosurg 2020: 1-9. DOI: 10.1080/02688697.2020.1742291.

59. Di Rienzo A, Pangrazi PP, Riccio M, Colasanti R, Ghetti I, Iacoangeli M. Skin flap complications after decompressive craniectomy and cranioplasty: Proposal of classification and treatment options. Surg Neurol Int 2016; 7 (Suppl 28): S737-S745. DOI: 10.4103/2152-7806.193724.

60. Shih FY, Lin CC, Wang HC et al. Risk factors for seizures after cranioplasty. Seizure. March 2019; 16: 15-21.

61. Spencer R, Manivannan S, Sharouf F, Bhatti MI, Zaben M. Risk factors for the development of seizures after cranioplasty in patients that sustained traumatic brain injury: A systematic review. Seizure 2019; 69: 11-16.

Received November 12, 2020. Accepted November 25, 2020. 